\title{
Poverty status and cigarette smoking prevalence and cessation in the United States, 1983-1993: the independent risk of being poor
}

\author{
Alan I Flint, Thomas E Novotny
}

\begin{abstract}
Objective-To analyse the independent relations between poverty status and cigarette smoking prevalence and cessation in the United States, 1983-1993.

Design-An analysis of eight crosssectional national surveys.

Setting-The United States, 1983-1993. Participants-236 311 civilian, noninstitutionalised adult residents of the United States, aged 18 years and older.

Main outcome measures-Probability of current cigarette smoking and proportion of former smokers among ever-smokers (quit ratio) in surveyed subjects below the poverty threshold, compared with those at or above the poverty threshold.

Results-The odds ratio for current smoking among persons below the poverty threshold ranged from a low of 1.10 in 1985 to a high of 1.45 in 1990 , and remained between 1.26 and 1.30 during 1991-1993. The odds ratio for smoking cessation (quit ratio) among persons below the poverty threshold ranged from 0.81 in 1985 to 0.64 in 1991, and remained between 0.73 and 0.66 during 1991-1993. These measures of the relations between poverty status and smoking were derived using multiple logistic regression models, which adjusted for the effects of sex, age, education, race, employment status, marital status, and geographic region.
\end{abstract}

Conclusions-Persons below the poverty threshold continue to be more likely than those at or above the threshold both to be current smokers and not to have quit. Poverty may be an indicator of underparticipation in the changing social norms regarding smoking behaviour in recent years. Individuals below the poverty threshold may need focused efforts to help achieve the Healthy People 2000 objectives for reducing adult smoking prevalence. Further understanding of the relation between poverty and smoking is essential to develop effective programmes for this vulnerable population subgroup.

(Tobacco Control 1997;6:14-18)

Keywords; poverty; smoking prevalence
Cigarette smoking is a major preventable cause of morbidity and mortality in the United States ${ }^{32}$ and remains a major public health priority. $^{2}$ Year to year trend analyses of cigarette smoking prevalence and cessation provide a better understanding of determinants of smoking and directions for intervention. Recent reports show a steady decrease in smoking prevalence and a steady increase in smoking cessation, ${ }^{3}$ but differences have been reported in the change in snoking rates over time according to geographic region, educational attainment, ${ }^{5}$ race, sex, $^{6}$ and household income. ${ }^{7}$ However, many analyses do not adjust for potential confounding effects of important sociodemographic factors. One multivariate analysis of 1985 National Health Interview Survey (NHIS) data suggested a small relation between poverty status (a United States Census defined household income measure which is adjusted for size, composition of household, and inflation) and smoking in that year. ${ }^{8}$ The US Centers for Disease Control and Prevention (CDC) recently reported that, in 1993, the prevalence of current smoking among persons below the poverty threshold was higher than for those at or above the poverty threshold. ${ }^{3}$ This study presents an analysis of the change over time of cigarette smoking prevalence and cessation by poverty status, adjusting for potential confounding effects of other sociodemographic factors, using NHIS data from 1983 to 1993.

\section{Methods}

STUDY POPULATON AND DATA

The NHIS has been conducted by the National Center for Health Statistics (NCHS) since 1957. Detalls of survey design and sampling methods have been reported in NCHS publications." The NHIS is a cross sectional sample survey of the non institutionalised civilian population of the United States. Detailed information on smoking behaviour was collected in 1983 , $1985,1987,1988,1990,1991,1992$, and 1993. In each of these years, between 21028 and 44233 persons were surveyed in person of by telephone. Of 274308 total respondents $250184(91.2 \%)$ provided information that permitted classification of the respondent as being atabove or below the US census povert threshold ${ }^{3+12}$ and $236311(86.1 \%)$ provided all 
Table 1 Distribution of subjects'sociodemographic characteristics, * by poverty status, Tational Health Interview surveys, 1983-1993 combined

\begin{tabular}{lcc}
\hline & $\begin{array}{c}\text { At/above poverty threshold } \\
(n=217 \text { 244) }\end{array}$ & $\begin{array}{l}\text { Below poverty threshold } \\
(n=32940)\end{array}$ \\
\hline Characteristics & & \\
\hline Sex, \% & 50.9 & 61.5 \\
Female & 49.1 & 38.5 \\
Male & 43.8 & 38.9 \\
Age (years), mean & 56.8 & 78.7 \\
Education, \% & 43.2 & 21.3 \\
Hight school diploma or less & & \\
Beyond high school & 90.9 & 72.3 \\
Race, \% & 9.1 & 27.7 \\
White & & \\
Black & 68.3 & 36.8 \\
Employment status, \% & 3.1 & 9.2 \\
Employed & 28.6 & 54.0 \\
Unemployed & & \\
Not in the work force & 68.9 & 38.4 \\
Marital status, \% & 6.0 & 10.7 \\
Married & 8.4 & 16.6 \\
Widowed & 16.6 & 34.3 \\
Divorced/separated & & 15.6 \\
Never married & 21.7 & 23.9 \\
Geographical region, \% & 25.4 & 41.6 \\
Northeast & 31.7 & 19.0 \\
Midwest & 21.2 & \\
South & & \\
West & &
\end{tabular}

Columns within each category may not sum to $100.0 \%$ due to rounding.

* $\mathrm{P}$ values for all sociodemographic characteristics by poverty status were $<0.001$; $\mathrm{P}$ values generated from either $\chi^{2}$ test or $t$ test. A $\chi^{2}$ test was used for categorical variables (sex, education, race, employment status, marital status, and geographical region) and a $t$ test was used for the continuous variable (age)

of the sociodemographic data necessary for the final analysis. Before 1983, the NHIS did not specifically collect information that would permit determination of poverty status.' In the years since 1983 that are not included in the study, the NHIS did not include information on smoking. Beginning with the 1985 survey, the NHIS oversampled blacks to obtain better estimates for this group. Postsampling stratification and weighting are designed to adjust for this oversampling effect. ${ }^{10}$

\section{VARIABLES}

Poverty status was assigned based on individual respondents' household income, size, and composition, according to the US census' threshold definition, which is adjusted annually for inflation, as measured by the consumer price index."

Current smokers for 1983-1992 were those individuals who answered "yes" to both of the following questions: (1) Have you smoked at least 100 cigarettes in your entire life? and (2) Do you smoke cigarettes now? For a second 1992 survey and the 1993 survey, the NCHS broadened the definition of current smoker to

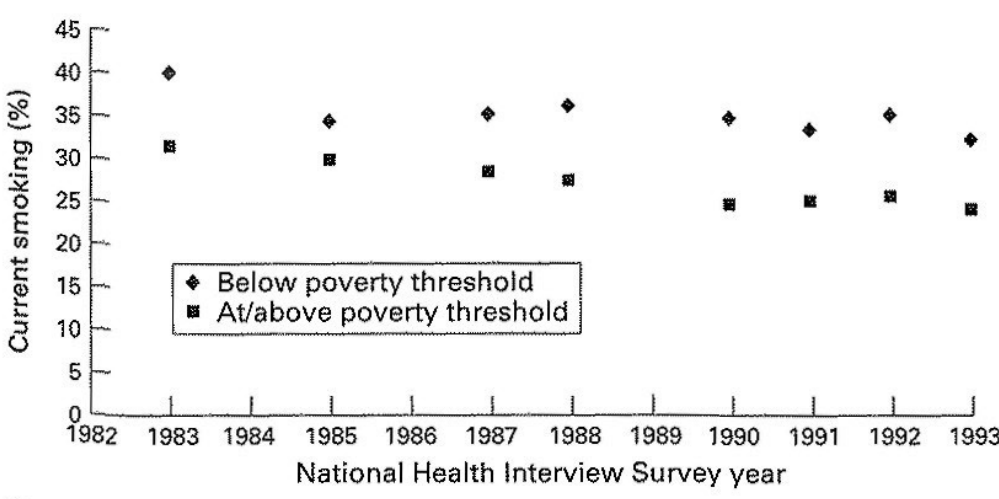

Figure 1 Prevalence (unadjusted) of current smoking among persons below and atiabove the poverty threshold, National Health Interview Survey, United States, 1983-1993. include intermittent smokers. ${ }^{12}$ In our study, data from the two 1992 surveys were combined using the method described by the CDC. ${ }^{12}$ Former smokers were defined in all years as those who reported that they had smoked at least 100 cigarettes in their lifetime but did not currently smoke. Cessation was assessed by the quit ratio, a cross sectional measure of the proportion of ever-smokers who are former smokers. ${ }^{45}$ Prevalence and quit ratio outcomes were examined dichotomously, according to poverty status, using logistic regression models.

Sex, age, race (black, white), education (high school or less, beyond high school), employment status (employed, unemployed, or not in the work force), and marital status (married, widowed, divorced/separated, or never married) were self reported, and geographic region (northeast, midwest, south, or west) was recorded by the examiner, based on the respondent's place of residence. Only surveys completed by those identifying themselves as black or white $(95.9 \%)$ were included in the analysis because of limited sample sizes of other racial and ethnic groups. Individual identification as Hispanic versus non-Hispanic was assessed by a separate survey item which was not considered in the race categorisation.

\section{STATISTICAL ANALYSIS}

Because of the complex sampling design of the NHIS, all data analyses included appropriate weighting and sampling adjustments. ${ }^{13}$ Age was analysed as a continuous variable. All other variables were analysed categorically. Comparisons of sociodemographic characteristics of those at or above $v$ below the poverty threshold were made using a $\chi^{2}$ test for categorical variables and a $t$ test for continuous variables. For the unadjusted analysis, a logistic regression model containing only a poverty status term was applied. For the adjusted analysis, a consistent unconditional logistic regression model was developed using stepwise analysis, starting with a hierarchically well formulated model including both main effects and interaction terms (none of which contributed consistently). ${ }^{14} 15$ This model was applied separately to data for each of the eight survey years included in the analysis. The final model contained terms for poverty status, sex, age, education, race, employment status, marital status, and geographic region; all of which contributed to the model in at least two years. Data management and preliminary analyses were performed using SAS, ${ }^{16}$ and final weighting and sampling design adjusted analyses were conducted using SUDAAN. ${ }^{17}$

\section{Results}

POVERTY STATUS

Table 1 shows the sociodemographic characteristics of those at/above and below the poverty threshold for the years 1983-1993 combined. Sex, age, education, race, employment status, marital status, and geographical region were all related to poverty status. 
Table 2 Odds ratios for current smoking among persons below the paterty threshold ${ }^{*}(v$ at labove the poverty threshold), National Healih Interview surveys, Unitod States, $1983-1993$

\begin{tabular}{lll}
\hline Survey year & Unadjusted odds ratio $(95 \% \text { CD }\}^{4}$ & Adjusted odds ratio $(95 \%$ Ol)f \\
\hline 1983 & $1.46(1.30-1.64)$ & $1.23(1.08-1.41)$ \\
1985 & $1.23(1.13-1.35)$ & $1.10(1.00-1.21)$ \\
1987 & $1.38(1.26-1.52)$ & $1.21(1.11-1.32)$ \\
1988 & $1.52(1.38-1.68)$ & $1.32(1.20-1.44)$ \\
1990 & $1.63(1.49-1.78)$ & $1.45(1.33-1.59)$ \\
1991 & $1.51(1.38-1.64)$ & $1.29(1.17-1.42)$ \\
1992 & $1.57(1.39-1.77)$ & $1.30(1.16-1.47)$ \\
1993 & $1.51(1.33-1.70)$ & $1.26(1.11-1.43)$ \\
\hline
\end{tabular}

* Defined by United States Census using housefold size, income, and composition. $\$ C l$, conficience interval.

fadjusted for effects of sex, age, education, race, employment status, marifal status, and geographical region.

$\$ 0$ dds ratio is not significantiy difterent from 1.00 , at $\mathrm{P}<0.05$.

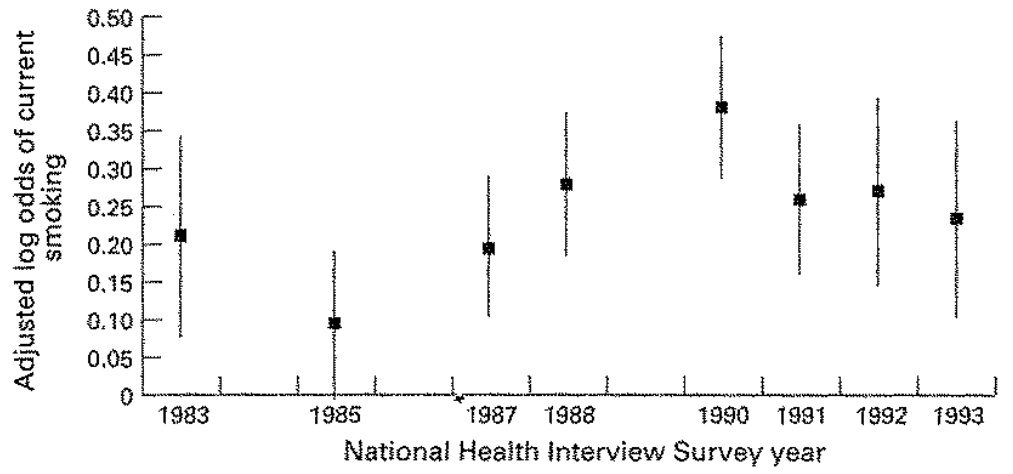

Figure 2 Adjusted log odds (writh 95\% confidence intervals) for current smoking among persons below the poverty threshold, National Healih Interviats Survey, Unted States, $1983-1993$

Table 3 Odds ratios for smoking cessation (oist ratio) among persons below the poveryy threshold * (v atfabove the poverty threshold), National Health Interwiew surveys, Urited Statss, 1983-1993

\begin{tabular}{|c|c|c|}
\hline Survey yeat & Unadizusted otds ratio $(95 \% \mathrm{Cl}) \mathrm{t}$ & Adjusted odds ratio $(95 \%$ Cl) $*$ \\
\hline 1983 & $0.42(0.35 \cdots 0.49)$ & $0.70(0.57+0.85)$ \\
\hline 1085 & $0.54(0.48-0.60)$ & $0.81(0.72-0.92)$ \\
\hline 1987 & $0.45(0.40 \cdots 0.50)$ & $0.72(0.64-0.81)$ \\
\hline 1988 & $0.44(0.39-0.49)$ & $0.69(0.61,0.78)$ \\
\hline 1990 & $0.39(0.35-0.45)$ & $0.64(0.56-0.72)$ \\
\hline 1991 & $0.41(0.36-0.46)$ & $0.68(0.59 n-0.77)$ \\
\hline 1992 & $0.44(0.37-0.51)$ & $0.73(0.61-0.87)$ \\
\hline 1993 & $0.40(0.3 k-0.46)$ & $0.66(0.56 m-0.78)$ \\
\hline
\end{tabular}

*Defined by United States Census asing household size, income, and composition. tCl indicates confidence interval.

fAdjusted for effects of sex, age, education, race, employment starus, marital status, and geographical region.

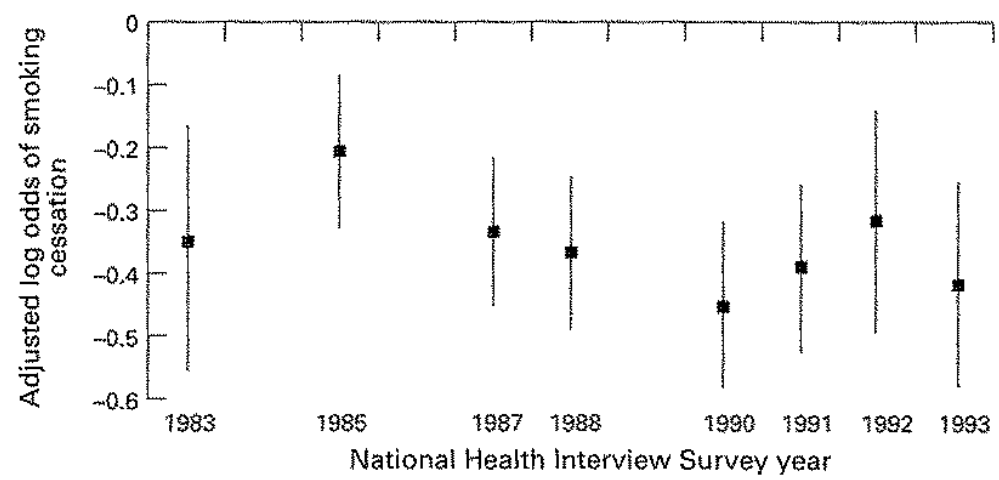

Figure 3 Adjusted log odds (with 95\% confidence intervats) for smoking cessation (quit ratio) among parsans below the poverty threshold, National Fealth Interviequ Survey. United States, 1983 1993.

SMOKING PREVALENCE

Figure 1 shows the overall unadjusted prevalence of current smoking by poverty status from 1983 to 1993 . Those below the poverty threshold declined in prevalence 0 current smoking from $40.2 \%$ in 1983 to $32.0 \%$ in 1993. Those at or above the poverty thresh old declined from $31.5 \%$ in 1983 to $23.8 \%$ ir 1993.

The left side of table 2 shows the unadjustec odds ratios and $95 \%$ confidence intervals o current smoking given poverty status below th poverty threshold for each of the survey year from 1983 through 1993, which ranged fron 1.23 to 1.63 . The right side of table 2 show adjusted odds ratios and $95 \%$ confidenc intervals by year, derived from the multipl logistic regression model, controlling for sey age, education, race, employment status, mar tal status, and geographical region. Th adjusted odds ratios for current smokin ranged from $1.10(95 \%$ confidence interv: included 1.00 ) in 1985 to 1.45 in 1990 . In th most recent three years of analysis, 1991-199: the adjusted odds ratios ranged from 1.261 1.30 .

Figure 2 shows the adiusted log odds an $95 \%$ confidence intervals of current smokir among those persons below the pover threshold, illustrating changes over time.

\section{SMOKANG CESSATION}

The left side of table 3 shows the unadjuste odds ratios and $95 \%$ confidence intervals smoking cessation given poverty status belo the poverty threshold from 1983 to $19 \mathrm{c}$ (range 0.54 to 0.39). The right side of table shows the adjusted odds ratios and $95 \%$ con dence intervals, derived from the multip logistic regression model, controlling for se age, education, race, employment status, mat tal status, and geographical region, all of whi were significantly less than 1.0 (range 0.81 1985 to 0.64 in 1990). The odds ratios signi cantly less than 1.0 indicate that those bel the poverty threshold were significantly le likely to be quitters than those at or above $t$ poverty threshold. In the most recent thr years, 1991-1993, the adjusted odds rati ranged from 0.66 to 0.73 . Figure 3 shows adjusted $\log$ odds for of smoking cessati among those below the poverty threshold or time.

\section{Discussion}

While overall trends in recent years show slow decline in current smoking and a sl incline in quit ratio in the United States, $d$ results suggest that persons below the pove threshold have been and continue to be at $\mathrm{s}$ nificantly higher risk both to be current smi ers and not to have quit smoking. From 19 on, those below the poverty threshold $w$ consistently found to be more likely ro be $c$ rent smokers than those at or above the pove threshold, even after adjusting for sex, a education, race, employment status, man status, and geographical region. Similarly, $p$ sons below the poverty threshold were 1 likely to be quitters throughout the stu period. Although blacks, women, individuals with lower educational attainm seem to be overrepresented below the pove threshold, adjusting for these factors did 
explain the relation between poverty status and smoking. In reviewing the findings from the most recent years in figs 1 and 2 , there seems to have been no recent improvement in the risk of smoking among the poor.

Cigarette smoking is a complex behaviour with several identifiable socioeconomic, demographic, and psychosocial determinants. Poverty status probably represents determinants that extend beyond issues of individual or household income. Indeed, individuals residing in federally designated poverty areas have been found to be at increased risk of all cause mortality, even after adjusting for race, income, and employment status. ${ }^{18}$ Further research may be needed to understand why poverty is a persistent independent marker of cigarette smoking among adults. It may be that those below the poverty threshold differ in other ways. Understanding these differences by further study of NHIS data and other data sources may provide better understanding of our findings.

Excluding individuals with missing data is a possible limitation of our study. Of all those surveyed, $98.5 \%$ provided the necessary information on smoking status; it is unlikely that excluding the $1.5 \%$ with unknown smoking status would have substantially affected our findings. Information on poverty status, however, was lacking in $8.8 \%$ of survey respondents who declined to answer questions relating to their household's income, size, or composition. However, current smoking prevalence in the group with missing information on poverty status was very similar to that in the at/above poverty threshold group in all years. In an effort to evaluate the potential bias introduced by necessarily excluding those for whom poverty status information was lacking, we performed trend analyses for ever-smoking (the most fundamental of smoking status assessments), comparing those excluded (for lack of information on poverty status) to those who did provide information on poverty status. While the prevalence of ever-smoking was consistently lower for those lacking information on poverty status than for those with information on poverty status (ranging from 1.1 to 3.9 percentage points in each year), the modelled slopes (change in ever-smoking by year) for these two groups did not differ $(z=0.34, P>$ 0.35 ). Although we cannot rule out selection bias in excluding the $8.8 \%$ of survey subjects who did not report sufficient information on household income, size, and composition, we have no reason to expect that those excluded would systematically differ from those included with regard to changing smoking status over time.

Although the National Health Interview Survey is a nationally representative sample survey, all sociodemographic groups may not be sampled equally. While differences were observed between those at/above and those below the poverty threshold, those below the threshold may be underrepresented in household based surveys.

Our findings have relevance for both health professionals and public health policy makers.
Broad public health efforts to educate the public about the ill health effects of smoking, to oppose tobacco advertising and promotion, and to support legislation restricting smoking in public places have coincided with the overall trends of decreasing prevalence and increasing cessation.' However, these efforts may not be reaching all socioeconomic groups equally. Poverty may be an indicator of underparticipam tion in the changing social norms regarding smoking behaviour in recent years. The relation of social class to mental illness and other comorbid conditions may also play a role. ${ }^{19}$ Given that poverty is also an independent predictor of poor health outcomes, ${ }^{18}$ such possibilities are particularly disturbing.

The nation's progress toward the Healthy People 2000 objectives must be continually reassessed. Although there are "special population" targets for current smoking prevalence for those with a high school education or less, blue collar workers, blacks, Hispanics, American Indians, those of Southeast Asian descent, women of reproductive age, pregnant women, and women using oral contraceptives, there is no specific target for low income populations. $^{2}$ Our findings suggest that individuals below the poverty threshold may need strengthened efforts (beyond those focused on blacks and women) to prevent recruitment of new smokers and to help those who already smoke to quit. If the Healthy People 2000 objectives are to be applied evenly to all income groups, the differentials reported here must also be better understood.

Ultimately, increased efforts to reduce smoking among the poor may lead to decreased rates of smolking related morbidity and mortality in years to come.

This paper was presented at the American Heart Association's 36 th Annual Conference on Cardiovascular Disease Epidemiology and Prevention, San Francisco, 15 March, 1996. This work was supported by grants (T32 HLO7365 and U48/CCU909706-03) from the National Heart, Lung, and Blood Institute, and the Center for Family and Community Health, under a cooperative agreement with the US Centers for Disease Control and Prevention.

1 US Dept of Health and Human Services. Reducing the health conseguences of smoking: 25 years of progress. A report of the Surgeon General, 1989. Rockville, Maryland: Public Health Surgeon General, 1989. Rockville, Maryland: Public Healu Service, Centers for Disease Control, National Center for on Smoking and Health, 1989. (DHHS Publication No on Smoking and

2 US Dept of Health and Human Services. Healthy people 2000: National health promotion and disease prevention objectives. Washington, DC: US Government Printing Office, 1991. (DHHS Publication No (PHS) 91-50212.)

3 US Centers for Disease Control and Prevention. Cigarette smoking among adults-United States, 1993. MMWR 1994;43:925-30.

4 Marcus SE, Pierce JP, Giovino GA, Kleinman JC, Novotny TE. Regional trends in cigarette smoking behaviour in the United States. Tobacco Control 1992;1:107-13.

5 Pierce JP, Fiore MC, Novotny TE, Hatziandreu EI, Davis RM. Trends in cigarette smoking in the United States: educational differences are increasing. IAMA 1989; educational

6 Fiore MC, Novotny TE, Pierce IP, Hatziandreu EJ, Patel KM, Davis RM. Trends in cigarette smoking in the United States: the changing influence of gender and race. $7 A M A$ $1989 ; 261: 49-55$

7 Novotny TE, Shane P, Daynard RA, et al. Tobacco use as a sociologic carcinogen: the case for a public health approach. In: DiVita V, Hellman S, Rosenoerg SA, eds. Cancer prevention. Philadelphia: IB Lippincott, 1992.

8 Novotny TE, Wamer $\mathrm{KE}$, Kendrick JS, Remington PL. Smoking in blacks and whites: socioeconomic and demographic differences. Am 7 Public Health 1988;78:1187-9. 
9 Kovar MG, Poe GS. The National Health Interviect Surtey design, 1973-84, and procedures, 1975-83. Hyattsvilte, design, 1973-84, and procedures, 1975-83. Hyattswite, (DHHS Ptiblication No (PHS) 85.1320 . Vital and Health (DHiHs Ptiblication No (PFS)

10 Massey IT, Moore TF, Parsons VL, Tadros W. National

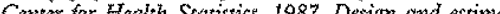
Center for Redith Statsstics 1987. Design and estimation for the Nazional Healh Interwew Survey, 1985-1994. HyattsPublication No (PHS) 89-1384. Viral and Health Publication No (FHS)

11 us Department of Commerce. 1990 Census of population, sacial and economic charatteristics, lyated States. US Departu ment of Commarce publication $1990 \mathrm{CP}-2-1$. Washing -

12 US Centers for Disease Control and Prevention. Cigarette smoking among adults-United States, 1992, and changes in the definition of current cigarette smoking. MMW $1994 ; 43: 342-6$.
$13 \mathrm{Cox} B G$, Cohen SB. Methodological issues for health care surweys. Nev York: Marcel Delkker, 1985.

14 Keintam DG. Logistic regression. New York; SpringerVerilag, 1994 .

15 Kleinbawn DG, Kupper LI. Applied yegression analysis and other mulivariable methods. Buston: Dixbury Press, 1978.

16 SAS Institute. SASISTAT user's guide. Version 6.08, the ed, Cary, North Carolina: SAS Institure, 1990.

17 Shah BV, Barnwell BG, Bieler GS. SUDA,AN softsare for the statistical analysis of correlazed datas user's mantial. Release $6.40,1995$. Research Triangie Park, North Carotina: Research Triangle Institute, 1995.

18 Haan M, Kaplan GA, Camacho T. Poverty ana heaith: prospective evidence from the Alameda cousry study. $A m$ f Epidemiol 1987;125:989-98.

19 Bromet Ef, Parkinson DK. Psychiatric disorders. In: Last $\mathrm{M}$, Wallace $\mathrm{RB}$, eds. Public health and preventive medicine. San Mateo, California: Appleton \& I lange, 1992

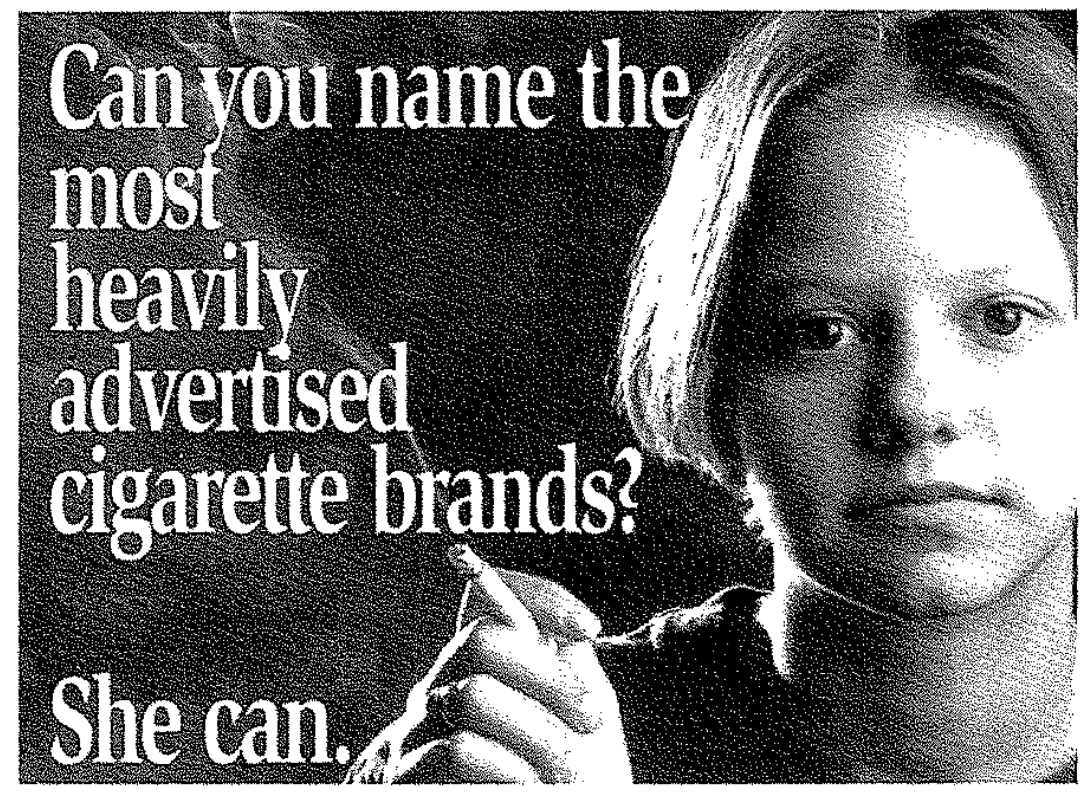

Eighty-five percent of chiddren who smoke prefer the three most advertised brands (Marboro, Camel and Newport). That's no coincidence.

Totacco companies spend billions on cartoon ads, biliboards near schools and mounkains of free merchandise that kids love (T-shirts, caps, backpacks, jackets). The results:

- Three thousand kids stant smoking every day.

* Nearly all adutt smokers begin as children.

- One-third will die from their addiction.

- Tobacco companies are making $\$ 200$ million a year from sales

to children and addicting a new generation of customers.

The nation's top health experts have proposed new limits to keep tobacco marketing from secucing children and to make cigarettes less accessible to kids. But industry lobbyists are scheming to snuff these rules out.

It's time we stopped trusting tobacco companies with our children's lives.

- Tell the FOA you suphort the proposed limits (Fond \& Drug

Administration, Docket 95No253, Room 1-23, 12420 Parklawn Drive,

Rockville, MD 20857).

- Tell your Members of Congress not to endanger Americas

children for tobacco company profits.

- Leam more by calling 1-800-284kIDS.

This ad sponsored by the Nationat PTA, American Nurses Association, National Association of Secondary Schoof Principals. National Coalition of Hispanic Health and Human Services Organizations (CosSMito) and over 100 other organizations throughout the country. 